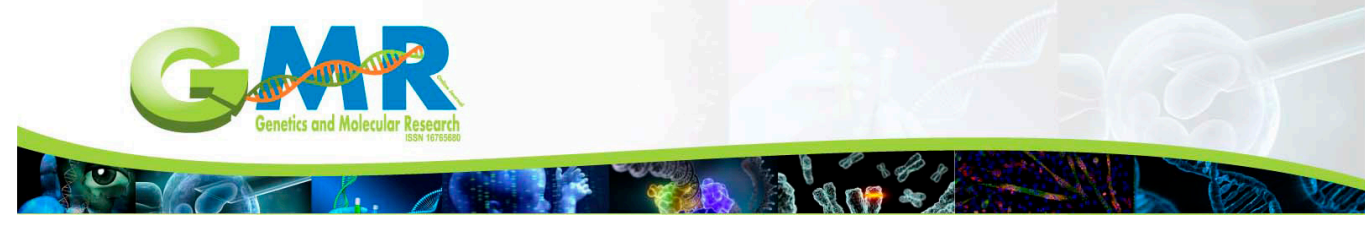

Corrigendum

\title{
PKR and HMGB1 expression and function in rheumatoid arthritis - Genet. Mol. Res. 14 (4): 17864-17870
}

Published online: December 22, 2015 (DOI: 10.4238/2015.December.22.11)

Corrected after publication: June 3, 2016 (DOI: 10.4238/gmr.150267861)

The correction is only in the name of the last author and should be:

W.J. Wang, S.J. Yin and R.Q. Guo 